\title{
PYRIDOXAL PHOSPHATE N-OXIDE. ANALYSES OF COENZYMATIC ACTIVITIES FOR TRYPTOPHANASE AND ASPARTATE AMINOTRANSFERASE BY USE OF STOPPED FLOW METHOD
}

\author{
Fuminori Masugi, Toshihiko Maeda, Yutaka Sumi, \\ Shoichi SHIMIzU, and Saburo FukUI ${ }^{1}$ \\ Laboratory of Industrial Biochemistry, Department of Industrial Chemistry, \\ Faculty of Engineering, Kyoto University, Kyoto, Japan
}

(Received January 24, 1973)

In order to obtain accurate information about the function of the ringnitrogen of $\mathbf{B}_{6}$ in the enzymatic reactions dependent on the vitamin, the reaction rate leading to $\alpha$-proton elimination from amino acid substrate was compared between native enzyme and holoenzyme species, reconstituted with pyridoxal phosphate N-oxide (PLP N-oxide), using a stopped flow method. In tryptophanase, the formation rate of the deprotonated Schiff's base $\left(\mathrm{A}_{502 \mathrm{~nm}}\right.$ complex $)$ of the PLP N-oxide enzyme with Lalanine was about one-fifth of that of the native enzyme, being substantially consistent with the marked low catalytic activity of PL N-oxide in the corresponding nonenzymatic model reaction and of the PLP Noxide enzyme in overall tryptophan degradation. This result strongly suggests that the electronegativity of the pyridinium-nitrogen plays a predominant role in the $\alpha$-proton elimination from the substrate, one of the most important steps in overall reaction.

On the other hand, in aspartate aminotransferase (GOT) reaction, such a significant difference was not observed between the formation rate of deprotonated Schiff's base of native GOT with erythro- $\beta$-hydroxyaspartate $\left(\mathrm{A}_{492 \mathrm{~nm}}\right.$ complex $)$ and that of the artificial GOT activated with PLP N-oxide. However, the reaction of PMP N-oxide form of GOT with $\alpha$-keto acid proceeded at an extremely slow rate as compared with that of PMP form of GOT. These phenomena indicate that the lower $V_{\max }$ of overall GOT reaction catalyzed by the PLP N-oxide-bound holoenzyme would be accounted for by the marked smaller reactivity of PMP N-oxide form with $\alpha$-keto acid. These results strongly suggest that, in GOT, the $\alpha$-proton elimination from substrate is mainly mediated by a nucleophilic attack of basic amino acid residue located at an appropriate position of enzyme protein and that the introduction of an

1 真杉文紀, 前田敏彦, 㲇見 裕, 清水祥一, 福井三郎 
oxygen atom into the pyridine-nitrogen of PLP results in a conformational change of coenzyme analog-bound GOT which renders the interaction between PMP-form GOT with $\alpha$-keto acid very difficult.

It is well established that vitamin $\mathrm{B}_{6}$-catalyzed enzymatic reactions proceed via the Schiff's base (aldimine) formation between pyridoxal phosphate (PLP) and amino acid substrate. Special properties of PLP enable the labilization of the bonds to the $\alpha$-carbon of the amino acid, leading to a variety of reactions, such as transamination, decarboxylation, racemization and splitting of the $\mathrm{C}_{\alpha}-\mathrm{C}_{\beta}$ bond of amino acid and so on. Model studies with analogs of pyridoxal (PL) permitted delineation of the structural features of the coenzyme required for its catalytic actions: Schiff's base formation between the formyl group at position 4 and amino acid is greatly favored by the phenol group at position 3, and, in the resulting complex, both the pyridine-nitrogen and the azomethine-nitrogen provide electrophilic groups so placed as to weaken each of the bonds about the $\alpha$-carbon atom of the amino acid. These concepts, derived largely from studies of nonezymatic model reactions, offered the basis for the general mechanism of reactions catalyzed by PLP $(1,2)$. In enzymatic reactions, however, it should be taken into consideration that both marked enhancement of reaction rate and strict stereospecificity are brought about by the contribution of apoprotein, as proposed by DUNATHAN (3) and other researchers.

To obtain further information on the role of pyridine-nitrogen of PLP for the exhibition of its coenzymatic activity, N-oxide of PLP (PLP N-oxide) was prepared in our laboratory $(4,5)$, and its catalytic activity $(4,5)$ as well as mode of binding to the apoproteins (6) in some enzyme systems were investigated. In general, the incorporation of oxygen atom into the pyridine-nitrogen of PLP decreased the coenzymatic activity in various $B_{6}$-enzyme systems. Moreover, a complicated phenomenon was observed in the binding step of PLP N-oxide to the apoprotein of aspartate aminotransferase (GOT) (6).

This paper describes the comparison of the catalytic activities of GOT and tryptophanase activated with PLP and with PLP N-oxide in the reaction rates up to the elimination of $\alpha$-proton from the amino acids by use of a stopped flow method.

\section{EXPERIMENTAL PROCEDURES}

Materials. Cytoplasmic and mitochondrial aspartate aminotransferases $\left(\mathrm{GOT}_{\mathrm{s}}\right.$ and $\left.\mathrm{GOT}_{\mathrm{m}}\right)$ were purified from pig heart muscle by the procedure of WADA and MoRINo (7). The apoenzymes were prepared according to the method of TURANo et al. (8) Apotryptophanase was obtained from E. coli B/1t-7A and converted to desired holoenzyme species according to the procedure of NewTON et al. (9) Pyridoxal phosphate N-oxide (PLP N-oxide) was prepared by our 
method (5) with a slight modification in its crystallization step. Erythro- $\beta$ hydroxy-DL-aspartate was synthesized by the method of KORNGUTH and SALLACH (10).

Protein concentration was determined by the method of LowRY et al. (11) with crystalline bovine serum albumin as standard. Absorption spectra were recorded with a Shimadzu Multipurpose Recording Spectrophotometer 50L and their rapid time-course changes were followed using a Hitachi Rapid Scan Spectrophotometer RSP-2 equipped with a stopped flow apparatus.

\section{THEORY}

Steady state kinetics of the Schiff's base formation

The Schiff's base formation reaction in a nonenzymatic system should be expressed in the following general equation.

$$
P+A \underset{k_{2}}{\stackrel{k_{1}}{\rightleftarrows}} S+\mathrm{H}_{2} \mathrm{O}
$$

where $P$, PL or PL N-oxide; $A$, amino acid; S, Schiff's base.

When amino acid is added to a PL or PL N-oxide solution, the change in absorbance at $420 \mathrm{~nm}\left(\mathrm{~A}_{420}\right)$ is related to the dissociation constant of the Schiff's base between amino acid and PL or PL N-oxide according to the following theoretical equation. When coenzyme analog has no absorption at $420 \mathrm{~nm}$ :

$$
\frac{P_{0}}{A_{420}}=\frac{1}{\varepsilon}+\frac{K}{\varepsilon \cdot A}
$$

When coenzyme analog has absorption at $420 \mathrm{~nm}$ :

$$
\frac{P_{0}}{A_{420}-\varepsilon_{0} \cdot P_{0}}=\frac{1}{\varepsilon-\varepsilon_{0}}+\frac{K}{\left(\varepsilon-\varepsilon_{0}\right) \cdot A}
$$

where $P_{0}$, the initial concentration of $P ; K$, dissociation constant of the Schiff's base in aqueous solution $\left(K=k_{2}{ }^{\prime} / k_{1}, k_{2}{ }^{\prime}=k_{2}\left(\mathrm{H}_{2} \mathrm{O}\right)\right) ; \varepsilon$ and $\varepsilon_{0}$, the apparent extinction coefficients of the Schiff's base and the coenzyme analog at $420 \mathrm{~nm}$. At high concentrations of the amino acid $(A)$, plots of $P_{0} / A_{420}$ or $P_{0} /\left(A_{420}-\varepsilon_{0} \cdot P_{0}\right)$ against $1 / A$ are linear and have an abscissa equal to $(-1 / K)$.

Kinetics of the Schiff's base formation in nonenzymatic systems

The relation of the concentration of the Schiff's base $(x)$ at time $t$ to $t$ can be expressed by the following equation.

$$
k_{1}\left(A_{0}+K\right) t=\ln \frac{1}{1-\frac{A_{0}+K}{A_{0} P_{0}} \cdot x} \quad\left(A_{0} \gg P_{0}\right)
$$

where $A_{0}$, the initial concentration of $A$. 
Equation 3 is the function of time $(t)$ and the concentration of the Schiff's base $(x)$. The Schiff's base of PL or PL N-oxide with valine usually absorbs at $420 \mathrm{~nm}$. Hence, the concentration of the Schiff's base was determined by measuring the absorbance at $420 \mathrm{~nm}$.

\section{Kinetics of the intermediate formation in enzymatic reactions}

The reaction scheme of tryptophanase is simply described as follows:

$$
E+S \rightleftarrows E X \rightleftarrows E+P
$$

where $E, S, E X$ and $P$ represent the holoenzyme, substrate, intermediate and product, respectively.

On addition of substrate, holotryptophanase exhibits a new absorption peak between 492 and $507 \mathrm{~nm}$ (the exact position is different according to the kind of substrate used). These peaks disappear as the substrate is decomposed to yield reaction products. L-Alanine also gives rise to an intense absorption band at $502 \mathrm{~nm}$. In contrast to the similar peak formed with the normal substrate of tryptophanase, this peak does not disappear even after long standing. The species absorbing at $502 \mathrm{~nm}$ represents a deprotonated enzyme-L-alanine complex (12).

In this case, the reaction scheme can be described as follows:

$$
E+S^{\prime} \underset{k_{2}}{\stackrel{k_{1}}{\rightleftarrows}} E X^{\prime}
$$

where $E, S^{\prime}$ and $E X^{\prime}$ represent the holoenzyme, L-alanine and the deprotonated enzyme-L-alanine complex, respectively. When L-alanine $\left(S^{\prime}\right)$ is added to an enzyme solution $\left(e_{0}\right)$, the change in absorbance at $502 \mathrm{~nm}$ is related to the dissociation constant of $E X^{\prime}\left(K=k_{2} / k_{1}\right)$ as follows:

$$
\frac{e_{0}}{A_{502}}=\frac{1}{\varepsilon}+\frac{K}{\varepsilon \cdot S^{\prime}} \quad\left(S^{\prime} \gg e_{0}\right)
$$

where $\varepsilon$ is the apparent extinction coefficient of the complex absorbing at $502 \mathrm{~nm}$.

The relation of the concentration of $E X^{\prime}(x)$ at time $t$ to $t$ is expressed by the following equation:

$$
k_{1}\left(e_{0}+K\right) t=\ln \frac{1}{1-\frac{S_{0}^{\prime}+K}{S_{0}^{\prime} e_{0}} x} \quad\left(S_{0}^{\prime} \gg e_{0}\right)
$$

When erythro- $\beta$-hydroxyaspartate is added to PLP-form of GOT, a new absorption peak appears at $492 \mathrm{~nm}$. This species represents a deprotonated enzyme-erythro- $\beta$-hydroxyaspartate complex (12). Equations 4 and 5 are also used for the 492-nm complex formation in GOT. 


\section{RESULTS}

Steady state of the Schiff's base formation of pyridoxal $N$-oxide with valine

The Schiff's base formation of PL and of PL N-oxide with valine of various concentrations was studied spectrophotometrically at different pHs. Figure 1 shows the results obtained according to Equations 1 or 2. From the data depicted in Fig. 1, the dissociation constants and apparent extinction coefficients of the Schiff's bases are given in Table 1. In general, the Schiff's base of PL N-oxide exhibited smaller dissociation constants than that of $\mathrm{PL}$ in the $\mathrm{pH}$ region tested. The former showed the smallest value at $\mathrm{pH} 7\left(9.52 \times 10^{-3}\right)$, while the latter was most stable at $\mathrm{pH} 9\left(1.41 \times 10^{-2}\right)$.
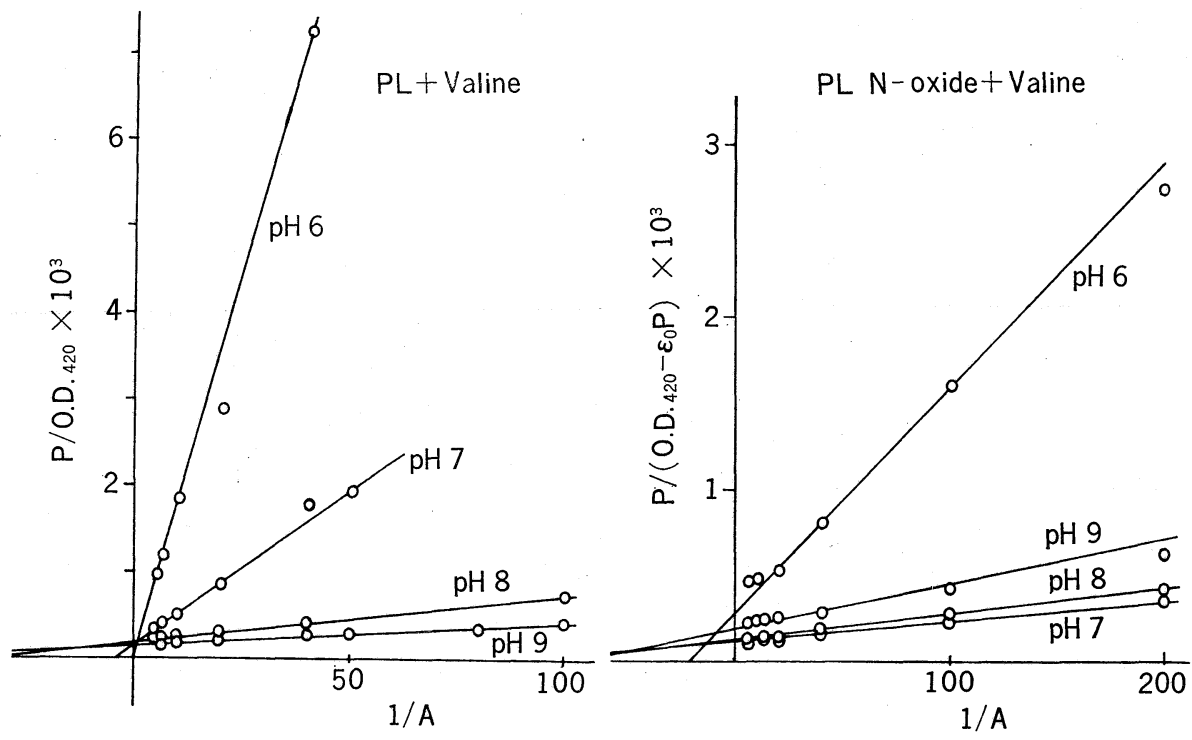

Fig. 1. Schiff's base formation between PL or PL N-oxide and DL-valine under various pH conditions. PL $\left(1.5 \times 10^{-4} \mathrm{M}\right)$ (left) and $\mathrm{PL} \mathrm{N}$-oxide $\left(1.5 \times 10^{-4} \mathrm{M}\right)$ (right) were incubated with various concentrations of DL-valine at different $\mathrm{pHs}$, respectively. The absorbance at $420 \mathrm{~nm}$ of the Schiff's bases formed was plotted against the concentrations of DL-valine according to Eq. 1. The buffer solution used was 0.05 м K-phosphate.

Table 1. Dissociation constants and extinction coefficients of the Schiff's base formed between valine and PL or PL N-oxide at various pHs. Buffer used: $0.05 \mathrm{M}$ potassium phosphate buffer.

\begin{tabular}{lllllll}
\hline & & pH 6 & pH 7 & pH 8 & pH 9 & $\lambda_{\max }$ \\
\hline PL & K $_{\text {diss. }}$ & 2.00 & $2.22 \times 10^{-1}$ & $3.58 \times 10^{-2}$ & $1.73 \times 10^{-2}$ & \multirow{2}{*}{415} \\
& $\varepsilon \times 10^{-3}$ & 6.66 & 6.66 & 6.66 & 6.66 & \\
PL N-oxide & $K_{\text {diss. }}$ & $4.76 \times 10^{-2}$ & $9.52 \times 10^{-3}$ & $1.22 \times 10^{-2}$ & $1.41 \times 10^{-2}$ & 409 \\
& $\varepsilon \times 10^{-3}$ & 3.27 & 5.86 & 5.67 & 3.71 & \\
\hline
\end{tabular}




\section{The rate constant of the Schiff's base formation}

In order to determine the rate constant for the Schiff's base formation, log $[1 /\{1-(A+K) \cdot x / A \cdot P\}]$ was plotted against time $(t)$ according to Eq. 3 . The results obtained are illustrated in Fig. 2. The forward and reverse rate constants $\left(k_{1}, k_{2}\right)$ of the Schiff's base formation were calculated from Fig. 2 by using the dissociation constants in Table 1 . The forward reaction constant $\left(k_{1}\right)$ is higher at $\mathrm{pH} 8$ than at pH 7 in the cases of both PL and PL N-oxide. At both pH 7 and 8 , the $k_{1}$ values for PL N-oxide were markedly large as compared with those for PL, whereas the $k_{2}$ values for PL N-oxide-valine aldimine were smaller than those for PL-valine aldimine (Table 2). Accordingly, it is concluded that PL N-oxide can form the Schiff's base with an appropriate amino acid such as valine more

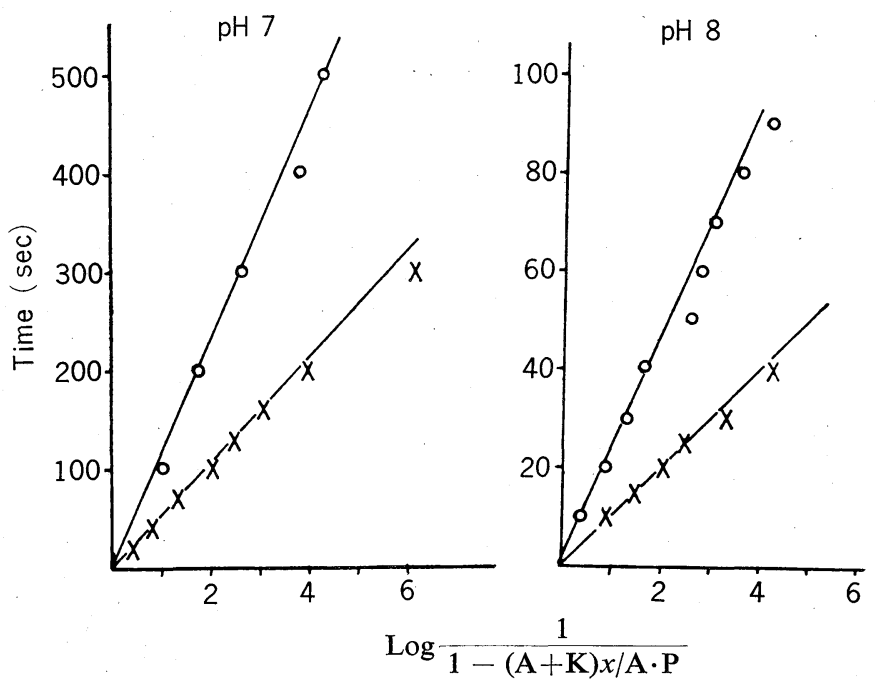

Fig. 2. Kinetics of Schiff's base formation between PL or PL N-oxide and DL-valine. PL $\left(3 \times 10^{-4} \mathrm{M}\right)(\mathrm{O})$ or PL N-oxide $\left(1.5 \times 10^{-4} \mathrm{M}\right)(\times)$ was mixed with DL-valine $(0.4 \mathrm{M})$ instantaneously by using a stopped flow apparatus equipped with flow generator. The absorbance at $420 \mathrm{~nm}$ was scanned against the time. $\log [1 /\{1-(A+K) \cdot x / A \cdot P\}]$ was plotted against the time according to Eq. 2 .

Left, at pH 7; right, at pH 8. The buffer solution used was $0.05 \mathrm{M} \mathrm{K}$-phosphate buffer in each case.

Table 2. Rate constants of Schiff's base formation.

PL or PL N-oxide + Valine $\underset{k_{2}}{\stackrel{k_{1}}{\rightleftarrows}}$ Schiff's base $+\mathrm{H}_{2} \mathrm{O}$.

\begin{tabular}{lccc}
\hline & & $\mathrm{pH}$ & $\mathrm{pH} 8$ \\
\hline PL & $k_{1}$ & $4.75 \times 10^{-3}$ & $4.42 \times 10^{-2}$ \\
& $k_{2}$ & $1.05 \times 10^{-3}$ & $1.84 \times 10^{-3}$ \\
PL N-oxide & $k_{1}$ & $2.07 \times 10^{-2}$ & $1.17 \times 10^{-1}$ \\
& $k_{2}$ & $1.97 \times 10^{-4}$ & $1.43 \times 10^{-3}$ \\
\hline
\end{tabular}


easily than PL and the resulting complex of PL N-oxide is less dissociable than that of PL at the neutral and weak alkaline $\mathrm{pH}$ regions where the GOT and tryptophanase reactions are carried out.

\section{The formation of $A_{502}$ complex in PLP N-oxide-bound tryptophanase}

The appearance of the absorption spectra of the deprotonated alaninetryptophanase complex was studied using the native holoenzyme and the holoenzyme activated with PLP N-oxide with different concentrations of L-alanine (Fig. 3). According to Eq. 4, the apparent dissociation constants were determined by plotting $1 / A_{502}$ against $1 /($ L-alanine) (Fig. 4 , Table 3 ). The apparent dissociation constant of PLP N-oxide enzyme-L-alanine complex was about five times
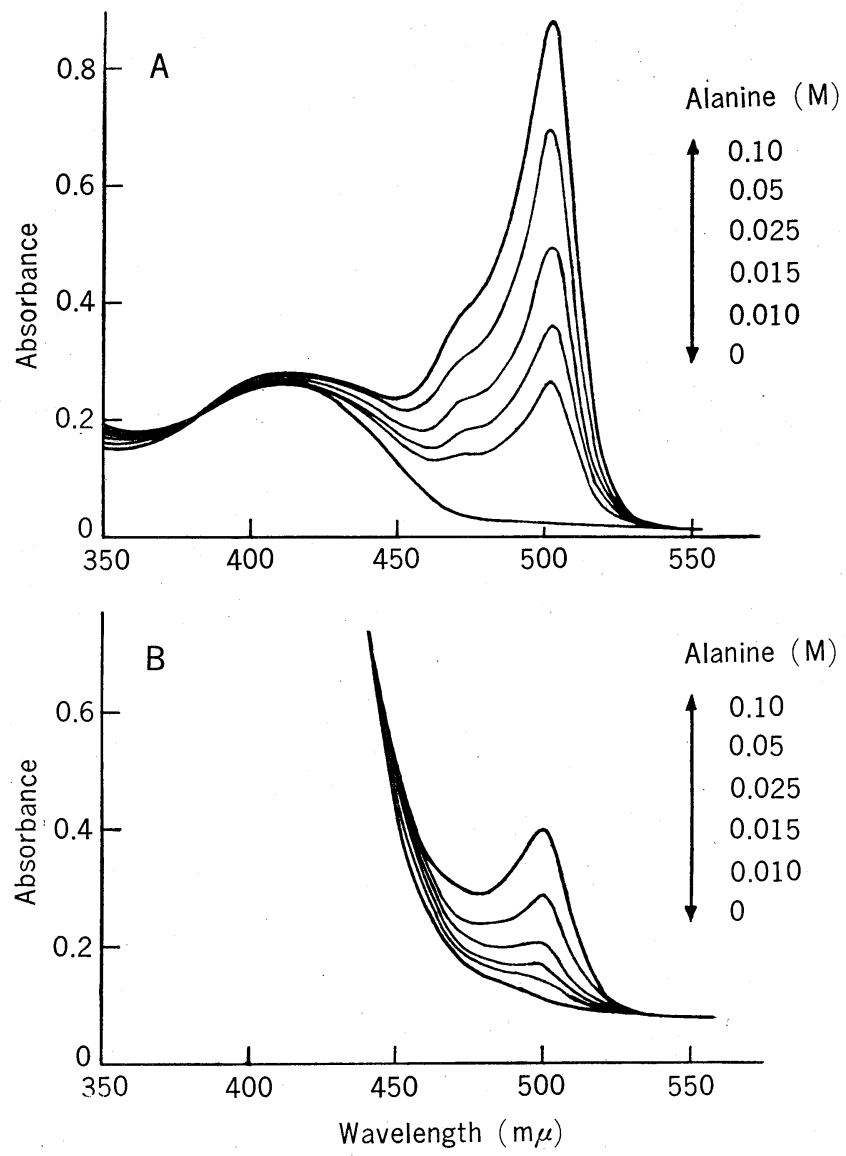

Fig. 3. Absorption spectra of tryptophanase-L-alanine complexes. Upper; holotryptophanase $(1.42 \mathrm{mg} / \mathrm{ml})$ was incubated with various concentrations of L-alanine at pH 8.0 (0.1 м phosphate buffer). Lower; holotryptophanase reconstituted with PLP $\mathrm{N}$-oxide $(11 \mathrm{mg} / \mathrm{ml})$ was incubated with L-alanine in the same way. 

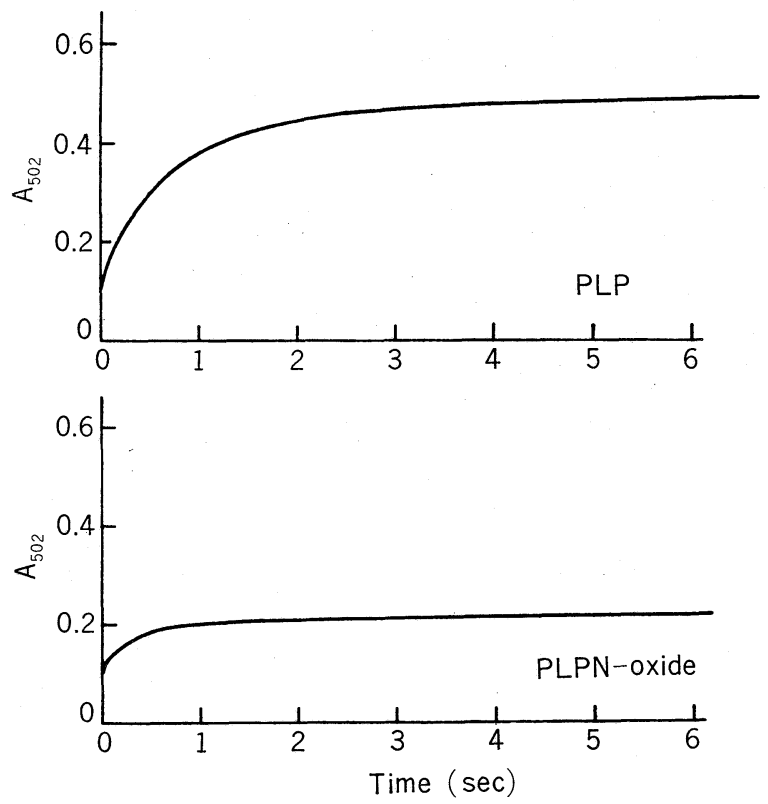

Fig. 4. Time course of $A_{502}$ complex formation. Upper; holotryptophanase $(2.96 \mathrm{mg} / \mathrm{ml})$ and L-alanine $(0.1 \mathrm{M})$ were mixed instantaneously by using a stopped flow apparatus equipped with flow generator. The change in absorbance at $502 \mathrm{~nm}$ with time was recorded by using a memoryscope. Lower; holotryptophanase reconstituted with PLP N-oxide $(6.7 \mathrm{mg} / \mathrm{ml})$ and $\mathrm{L}$-alanine $(0.5 \mathrm{M})$ were treated in the same way.

Table 3. Dissociation constant and rate constants of $E C S^{\prime}$ complex between tryptophanase and L-alanine.

\begin{tabular}{lccc}
$E C+S^{\prime} \underset{k_{-1}}{\stackrel{k_{1}}{\rightleftarrows}} E C S^{\prime}$ & & \\
& $\mathrm{K}_{\text {diss. }}=k_{-1} / k_{1}$ & & \\
\hline & $\mathrm{K}_{\mathrm{diss}}$ & $k_{1} 1 /(\mathrm{M} \cdot \mathrm{sec})$ & $k_{-1} 1 /(\mathrm{sec})$ \\
\hline PLP N-oxide enzyme & 0.22 & 1.85 & 0.407 \\
PLP enzyme & 0.042 & 9.53 & 0.396 \\
\hline
\end{tabular}

as large as that of PLP enzyme-L-alanine complex. In order to determine the rate constant of $502 \mathrm{~nm}$ complex formation, the absorption at $502 \mathrm{~nm}$ at time $(t)$ was followed by using a stopped flow apparatus (Fig. 4). According to Eq. 5, the rate constant of $502 \mathrm{~nm}$ complex formation was calculated from the abovementioned apparent dissociation constant (Table 3). The forward rate constant for the formation of PLP N-oxide enzyme-L-alanine complex was about one-fifth that of PLP enzyme-L-alanine complex. On the other hand, the reverse rate constant was almost equal in both PLP enzyme and PLP $\mathrm{N}$-oxide enzyme.

The formation of $A_{492}$ complex in PLP N-oxide-bound GOT

Figure 5 shows the absorption spectra of $\mathrm{A}_{492}$ complexes of PLP-bound GOT 

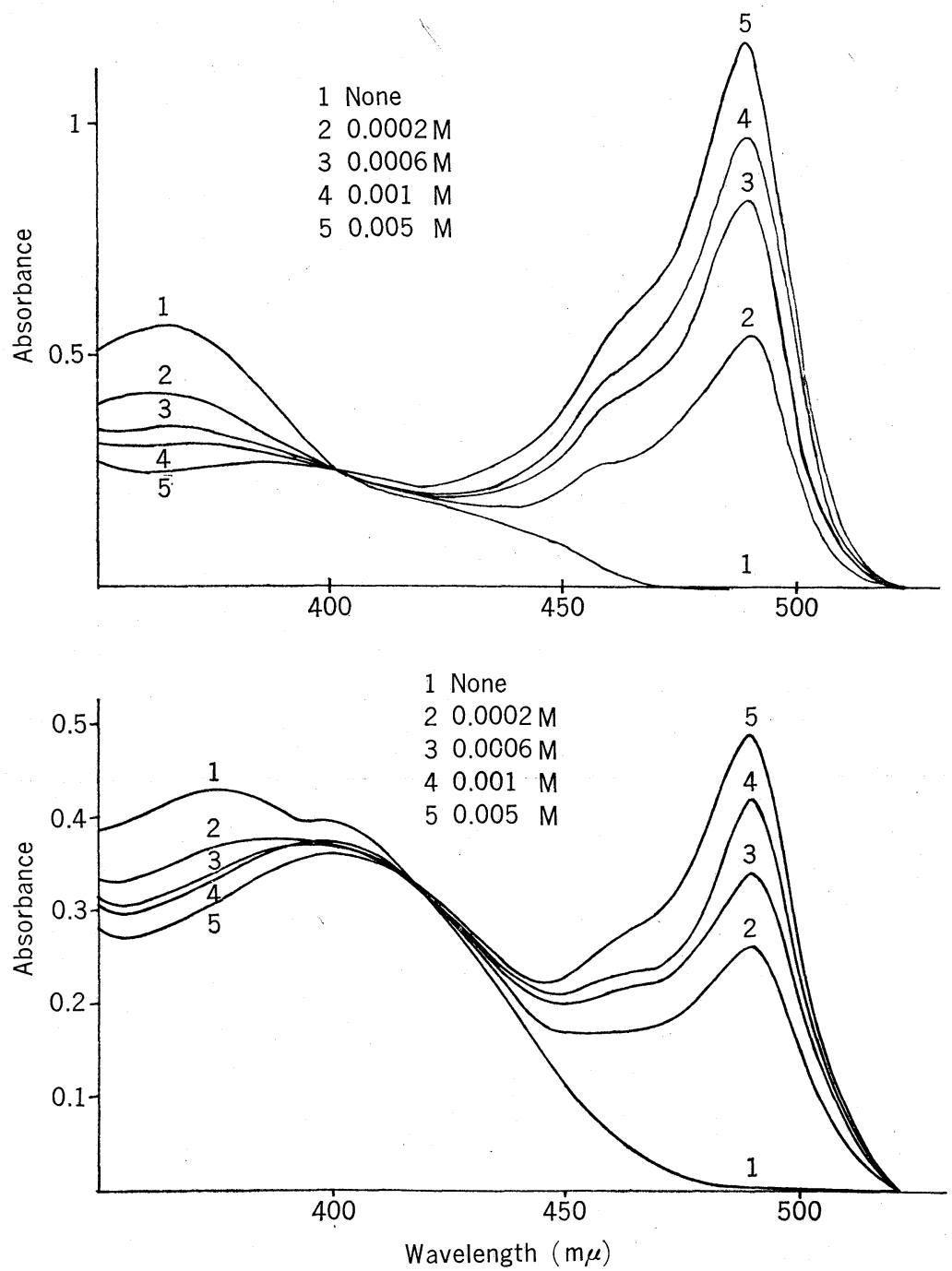

Fig. 5. Absorption spectra of GOT-erythro- $\beta$-hydroxyaspartate complexes. Upper; holoGOT $(5 \mathrm{mg} / \mathrm{ml})$ was incubated with various concentrations of erythro- $\beta$-hydroxyaspartate at $\mathrm{pH} 7.5(0.05 \mathrm{M}$ phosphate buffer). Lower; holoGOT reconstituted with PLP Noxide $(5 \mathrm{mg} / \mathrm{ml})$ was incubated with erythro- $\beta$-hydroxyaspartate in the same way.

(native GOT) and of PLP N-oxide-bound GOT using various concentrations of erythro- $\beta$-hydroxyaspartate. These spectra were obtained after standing the mixture of the enzyme and the substrate analog for $3 \mathrm{~min}$. According to Eq. 4, the reciprocal of absorption at $492 \mathrm{~nm}$ was plotted against the reciprocal of erythro$\beta$-hydroxyaspartate concentration (Fig. 6). From Fig. 6, the apparent dissociation constants of PLP-bound GOT-pseudosubstrate complex and of PLP N-oxide- 


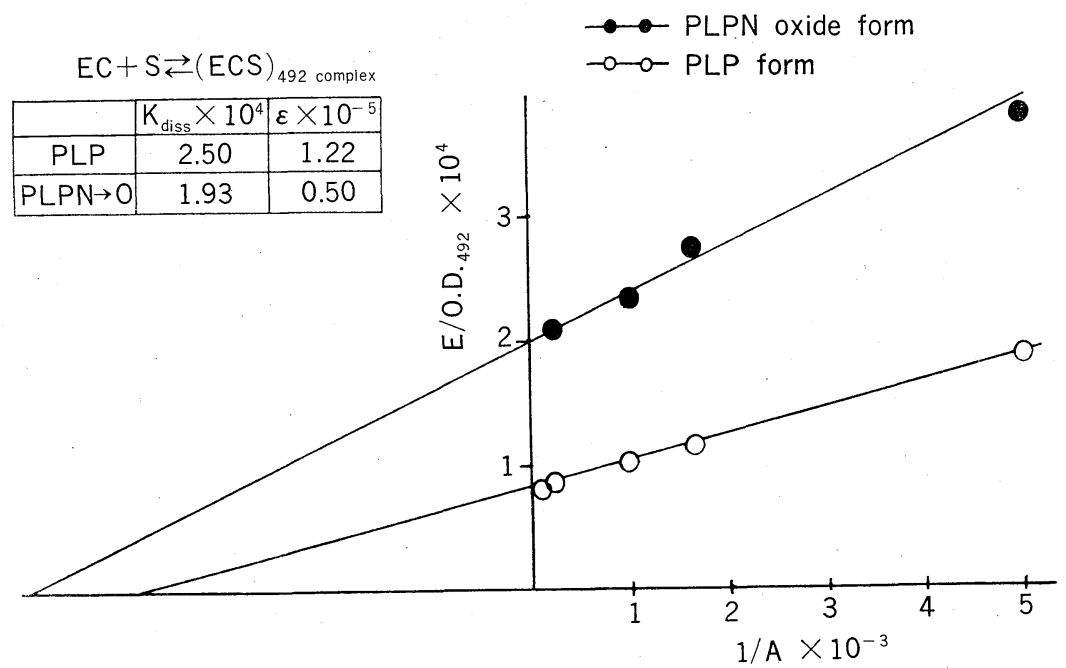

Fig. 6. Equilibrium of holoGOT-erythro- $\beta$-hydroxyaspartate complex formation at $\mathrm{pH}$ 7.5. The absorbance at $492 \mathrm{~nm}$ was plotted against the concentration of erythro- $\beta$ hydroxy according to Eq. 4. Closed circle, PLP N-oxide-enzyme; open circle, PLPenzyme.

bound GOT-pseudosubstrate complex were estimated graphically as $2.50 \times 10^{-4} \mathrm{M}$ and $1.93 \times 10^{-4} \mathrm{M}$, respectively. Next, the kinetics of the $A_{492}$ complex formation was studied. The time-course change of the absorbance at $492 \mathrm{~nm}$ was recorded using the stopped flow apparatus equipped with a memoryscope immediately after rapid mixing of PLP enzyme or PLP N-oxide enzyme with the substrate analog. As shown in Fig. 7, there was no marked difference between the PLP enzyme reaction and PLP N-oxide enzyme reaction. In the case of PLP enzyme, $A_{492}$ complex was formed instantaneously after mixing the enzyme and the pseudosubstrate. After several milliseconds, the absorbance increased further, suggesting the formation of an unidentified state having a higher extinction coefficient at $492 \mathrm{~nm}$. After 60 milliseconds, the absorbance at $492 \mathrm{~nm}$ gradually decreased and reached a constant level within 2.5 seconds. Thereafter, no change in the absorbance was observed at least during the subsequent $20 \mathrm{~min}$.

In the case of PLP N-oxide-bound GOT, the time-course change in the absorbance at $492 \mathrm{~nm}$ exhibited a substantially similar pattern, except that the state of having a high extinction coefficient at $492 \mathrm{~nm}$ observed in the case of PLP enzyme was not detected. The time-course study indicated that at least three steps would be involved in the reaction sequence leading to the deprotonated enzyme-substrate analog complex in both the native enzyme and the coenzyme analog-bound holoenzyme reactions, and that there exists no significant difference in the reaction rate up to the formation of the deprotonated complex between two enzymes. 

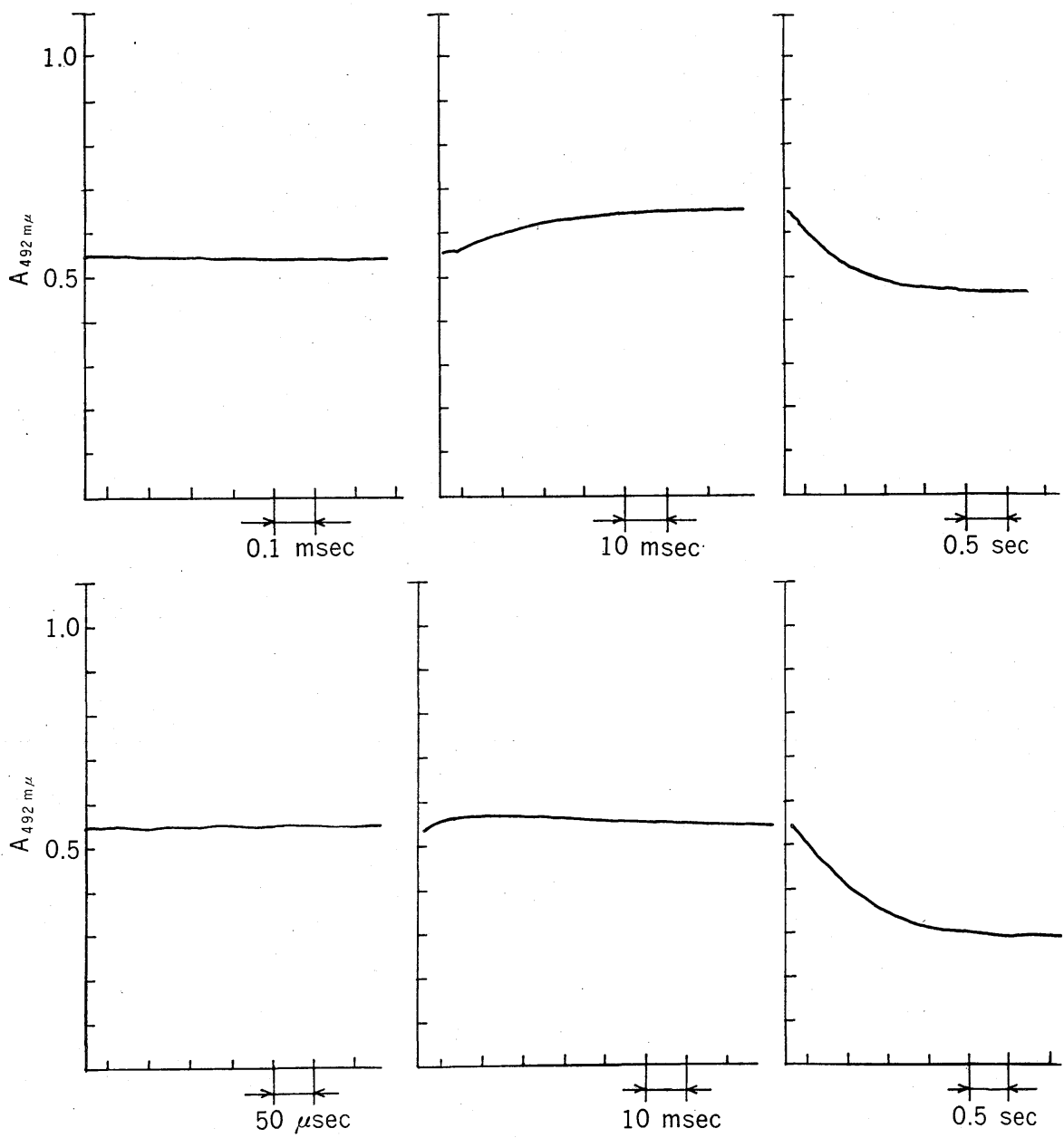

Fig. 7. Time-course of GOT-erythro- $\beta$-hydroxyaspartate complex formation. Upper; holoGOT $(5 \mathrm{mg} / \mathrm{ml})$ and erythro- $\beta$-hydroxyaspartate $(1 \mathrm{mM})$ were mixed instantaneously by using a stopped flow apparatus equipped with flow generator. The absorbance at $492 \mathrm{~nm}$ was recorded by using a memoryscope. Lower; holoGOT reconstituted with PLP N-oxide $(5 \mathrm{mg} / \mathrm{ml})$ and erythro- $\beta$-hydroxyaspartate $(2 \mathrm{mM})$ were treated in the same manner.

As reported previously $(4,5)$, the activity of GOT reconstituted with PLP $\mathrm{N}$-oxide was below one-half that of the native GOT in the overall reaction rate. This discrepancy could be accounted for by a significantly low reactivity of the GOT reconstituted with pyridoxamine phosphate N-oxide (PMP N-oxide) with $\alpha$-ketoglutarate, the reverse reaction from PMP-form GOT to PLP-form GOT. As shown in Fig. 8, the addition of $\alpha$-ketoglutarate to the PMP N-oxide-bound GOT resulted in a very slow change in the spectrum, indicating that the reaction 


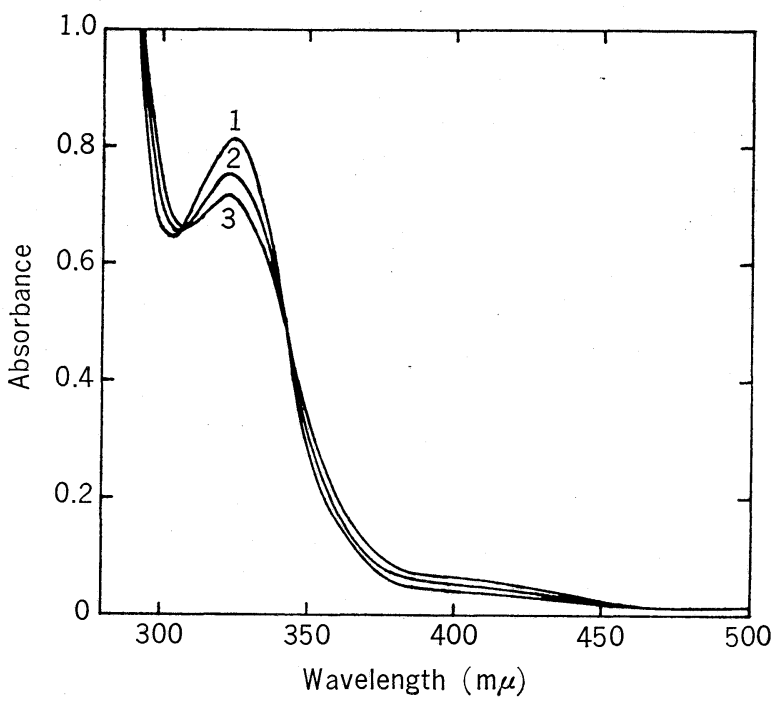

Fig. 8. Effect of $\alpha$-ketoglutarate on the PMP N-oxide form of GOT. PMP N-oxide form of GOT $\left(2.5 \times 10^{-5} \mathrm{M}\right)$ was incubated with $\alpha$-ketoglutarate $(10 \mathrm{mM})$ in $0.1 \mathrm{M}$ phosphate buffer ( $\mathrm{pH} \mathrm{7.0)}$ at $37^{\circ} \mathrm{C}$. Curves 1,2 , and 3 are the spectra measured at $5 \mathrm{~min}, 1.5 \mathrm{hr}$ and $6 \mathrm{hr}$ after mixing.

rate is markedly low as compared with that of the native PMP-form enzyme. Namely, it would be concluded that this step is rate-limiting in the overall reaction mediated by the coenzyme analog-bound GOT.

\section{DISCUSSION}

In model experiments of $\mathbf{B}_{6}$ enzyme-catalyzed reactions, it is clearly established that the pyridine-nitrogen, together with 4-formyl group and 3-phenolic hydroxyl group, is essential for the catalytic activity of PL(P). Initial activation of an
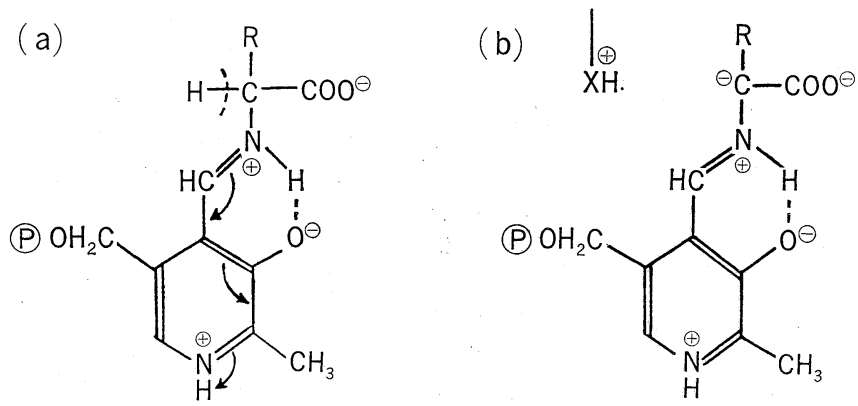

Fig. 9. Two proposed mechanisms for the $\alpha$-proton elimination from amino acid substrate. 
amino acid occurs through the formation of an aldimine (Schiff's base) between the amino acid and PL(P). The conjugated system of double bonds extending from the $\alpha$-carbon atom of the amino acid to the pyridinium-nitrogen of PL(P) results in a reduced electron density about the $\alpha$-carbon atom, thus weakening each of the bonds (Fig. 9a). One might assume that the same structural features that permit $\mathrm{PL}(\mathrm{P})$ to catalyze a given model reaction would be prerequisite to catalysis of the corresponding enzymatic reaction. In the case of enzymatic reaction, however, contribution of enzyme protein, especially that of a nucleophilic attack of the basic amino acid located at an appropriate position of enzyme, seems to take an important role for the labilization of proton attached to the $\alpha$-carbon atom of the amino acid substrate (Fig. 9b).

As reported in our previous paper (4), PL N-oxide showed markedly lower catalytic activities in various nonenzymatic model systems such as $\alpha, \beta$-elimination reactions of tryptophan and serine and transamination reaction between glutamate. The lower activity of PL N-oxide was attributed to the decreased electronegativity of pyridine-nitrogen, as discussed in our previous paper (4).

Table 4. Coenzymatic parameters of PLP N-oxide for several PLPdependent enzymes ${ }^{\mathrm{a}}$

\begin{tabular}{|c|c|c|c|}
\hline & \multicolumn{2}{|c|}{$\mathbf{K}_{\text {coenzyme }}(\mu \mathrm{M})$} & \multirow{3}{*}{$\begin{array}{c}\begin{array}{c}V_{\max }(\text { relative }) \\
\text { PLP N-oxide enzyme }\end{array} \\
\text { PLP enzyme }\end{array}$} \\
\hline & \multirow{2}{*}{ PLP enzyme } & \multirow{2}{*}{$\begin{array}{l}\text { PLP N-oxide } \\
\text { enzyme }\end{array}$} & \\
\hline & & & \\
\hline $\mathrm{GOT}_{\mathrm{m}}(\text { pig heart) })^{1)}$ & 1.19 & 1.19 & 0.45 \\
\hline $\mathrm{GOT}_{\mathrm{s}}(\text { pig heart) })^{1)}$ & 1.14 & 1.14 & $0.43^{b}$ \\
\hline D-Serine dehydratase $(E . \text { coli })^{2)}$ & +++ & ++ & 0.9 \\
\hline Tryptophanase $(E . \text { coli })^{11}$ & 4.5 & 5.0 & 0.65 \\
\hline \multicolumn{4}{|l|}{ Tyrosine phenol-lyase } \\
\hline \multicolumn{4}{|c|}{ Aspartate $\beta$-decarboxylase $(P s . \text { dacunhae })^{4)}$} \\
\hline Decarboxylation & & & 0.16 \\
\hline Desulfination & & & 0.26 \\
\hline Transamination & & & 0.31 \\
\hline
\end{tabular}

a In the case of muscle phosphorylase, PLP N-oxide was converted into PLP (PFEUfFER, T., Ehrlich, J. and Helmreich, E., Biochemistry, 11, 2125 (1972)

b In the case of $\mathrm{GOT}_{\mathrm{s}}$, the incorporation of one more mole of PLP N-oxide resulted in enhancement of the activity of the PLP N-oxide enzyme. The activated enzyme showed an almost similar $V_{\max }$ to that of the native enzyme (5). 1: data obtained by us (references 4 and 5), 2: by Dr. E. E. Snell (Vitamins and Hormones, 28, 265 (1970)), 3: by Dr. H. Yamada and Dr. N. Kumagai (personal communication), 4: by Dr. I. Chibata and Dr. T. Kakimoto (personal communication)

In various enzyme system, PLP N-oxide served as inferior coenzymes as listed in Table 4. For example, the activity of $\mathrm{GOT}_{\mathrm{m}}$ and $\mathrm{GOT}_{\mathrm{s}}$ reconstituted with PLP N-oxide was below one-half that of the PLP-enzymes, although binding of one mole of PLP N-oxide to a certain lysine residue at non-catalytic site rendered 
the activity of PLP N-oxide-bound GOT $_{\mathrm{s}}$ almost equal to that of the native enzyme (6).

In this paper, a stopped flow method was employed to compare PLP-enzyme and PLP N-oxide-enzyme in the reaction rate to form the deprotonated aldimine. In the case of tryptophan degradation, the relative activity of PLP N-oxide enzyme in overall enzymatic reaction was $c a .65 \%$, which was consistent with the relative activity of PL N-oxide to that of PL in the corresponding nonenzymatic reaction. The stopped flow study employed in this paper showed that the rate constant of $\alpha$-hydrogen elimination from L-alanine in PLP N-oxide-bound tryptophanase was remarkably small as compared with that in PLP-bound tryptophanase. These results strongly suggest that the participation of the electronegativity of pyridinenitrogen is most important for the $\alpha$-proton elimination from substrate in this system. In the case of GOT reaction, however, such a significant difference was not observed between the apparent rate of $\alpha$-proton elimination in PLPenzyme and in PLP N-oxide-enzyme, in contrast to the marked differences in both nonenzymatic and overall enzymatic reactions. This fact suggests that the electron-attracting force of the pyridinium-nitrogen of PLP does not play the important part in the $\alpha$-proton elimination step of GOT as expected hitherto. The low reaction rate of the overall GOT reaction mediated by the PLP N-oxide enzyme could be explained by the fact that the formation of PLP N-oxide-GOT was very difficult when PMP N-oxide-GOT was incubated with $\alpha$-ketoglutarate. As mentioned in our preceding paper (6), the $K_{\text {coenzyme }}$ value of PMP N-oxide for GOT was remarkably higher than that of PMP and the resulting PMP N-oxidebound holoGOT showed an extremely low $V_{\max }$ value as compared with the native enzyme. From these phenomena, it would be concluded that, in GOT, the function of the pyridine-nitrogen of PLP in the $\alpha$-proton elimination of amino acid substrate is significantly weak compared with that of the nucleophilic attack of the basic amino acid residue located at an appropriate position of the enzyme protein. The introduction of oxygen atom into the pyridine-nitrogen not only has some influence on the binding of the coenzyme analog with apoGOT but also leads to variations in the conformation of the resulting holoenzyme species. This conformational distortion would render the interaction between the amino group of PMP N-oxide form and the keto acid substrate more difficult than the case of the PMP enzyme, thus resulting in the decrease of the overall reaction rate.

The authors express their deep gratitude to Dr. H. Wada and Dr. Y. Morino, Osaka University School of Medicine, for supplying E. coli B/lt 7-A and to Dr. H. Yamada, Kyoto University, Research Institute for Food Science and to Dr. I. Chibata, Tanabe Pharmaceutical Co., for allowing us to quote from unpublished work. 


\section{REFERENCES}

1) Braunstein, A. E. and Shemyakin, M. M., Biokhimiya, 18, 393 (1953); Braunstein, A. E., in P. D. Boyer, H. Lardy, and K. Myrbäck (Editors), 2nd ed., The Enzymes, Academic Press, New York, Vol. II, p. 113 (1960).

2) Metzler, D. E., Ikawa, M., and Snell, E. E., J. Amer. Chem. Soc., 76, 648 (1954); Snell, E. E., Vitamins and Hormones, 16, 77 (1958).

3) Dunathan, H. C., Vitamins and Hormones, 28, 79 (1970).

4) Fukui, S., Ohishi, N., NAKaI, Y., and Shimizu, S., Arch. Biochem. Biophys., 130, 584 (1969).

5) Fukui, S., Oнishi, N., and Shimizu, S., Methods in Enzymol., 18, Part A, p. 598 (1969).

6) Masugi, F., Natori, Y., Shimizu, S., and Fukui, S., J. Nutr. Sci. Vitaminol., 1, 55 (1973).

7) WADA, H. and MoRINo, Y., Vitamins and Hormones, 22, 411 (1964).

8) Turano, C., Giartosio, F., Riva, F., and Baroncelli, V., Biochem. J., 104, 970 (1967).

9) Newton, W. A., Morino, Y., and Snell, E. E., J. Biol. Chem., 240, 1211 (1965).

10) Kornguth, M. L. and Sallach, H. J., Arch. Biochem. Biophys., 91, 39 (1960).

11) Lowry, O. H., Rosebrough, N. J., Farr, A. L., and Randall, J., J. Biol. Chem., 193, 265 (1951).

12) Jenkins, W. T., J. Biol. Chem., 239, 1742 (1964). 